\title{
Allometric Scaling of Clearance in Paediatric Patients: When Does the Magic of 0.75 Fade?
}

\author{
Elisa A. M. Calvier ${ }^{1}$ - Elke H. J. Krekels ${ }^{1}$ - Pyry A. J. Välitalo ${ }^{1}$. \\ Amin Rostami-Hodjegan ${ }^{2} \cdot$ Dick Tibboel $^{3} \cdot$ Meindert Danhof $^{1}$. \\ Catherijne A. J. Knibbe ${ }^{1,4}$
}

Published online: 10 August 2016

(C) The Author(s) 2016. This article is published with open access at Springerlink.com

\begin{abstract}
Allometric scaling on the basis of bodyweight raised to the power of 0.75 (AS0.75) is frequently used to scale size-related changes in plasma clearance $\left(\mathrm{CL}_{\mathrm{p}}\right)$ from adults to children. A systematic assessment of its applicability is undertaken for scenarios considering size-related changes with and without maturation processes. A physiologically-based pharmacokinetic (PBPK) simulation workflow was developed in $\mathrm{R}$ for 12,620 hypothetical drugs. In scenario one, only size-related changes in liver weight, hepatic blood flow, and glomerular filtration were included in simulations of 'true' paediatric $\mathrm{CL}_{\mathrm{p}}$. In a second scenario, maturation in unbound microsomal intrinsic clearance $\left(\mathrm{CL}_{\text {int,mic }}\right)$, plasma protein concentration, and haematocrit were also included in these simulated 'true' paediatric $\mathrm{CL}_{\mathrm{p}}$ values. For both scenarios, the prediction error (PE) of AS0.75-based paediatric $\mathrm{CL}_{\mathrm{p}}$ predictions was assessed, while, for the first scenario, an allometric exponent was also estimated based on 'true' $\mathrm{CL}_{\mathrm{p}}$. In the first
\end{abstract}

Electronic supplementary material The online version of this article (doi:10.1007/s40262-016-0436-x) contains supplementary material, which is available to authorized users.

Catherijne A. J. Knibbe

c.knibbe@antoniusziekenhuis.nl

1 Division of Pharmacology, Leiden Academic Centre for Drug Research (LACDR), Leiden University, Gorlaeus Laboratories, Einsteinweg, 552333 CC Leiden, The Netherlands

2 Manchester Pharmacy School, University of Manchester, Manchester, UK

3 Intensive Care and Department of Pediatric Surgery, Erasmus University Medical Center, Sophia Children's Hospital, Rotterdam, The Netherlands

4 Department of Clinical Pharmacy, St. Antonius Hospital, Nieuwegein, The Netherlands scenario, the PE of AS0.75-based paediatric $\mathrm{CL}_{\mathrm{p}}$ predictions reached up to $278 \%$ in neonates, and the allometric exponent was estimated to range from 0.50 to 1.20 depending on age and drug properties. In the second scenario, the PE sensitivity to drug properties and maturation was higher in the youngest children, with AS0.75 resulting in accurate $C_{p}$ predictions above 5 years of age. Using PBPK principles, there is no evidence for one unique allometric exponent in paediatric patients, even in scenarios that only consider size-related changes. As PE is most sensitive to the allometric exponent, drug properties and maturation in younger children, AS0.75 leads to increasingly worse predictions with decreasing age.

\section{Key Points}

There is no evidence for a universal allometric exponent for scaling drug plasma clearance $\left(\mathrm{CL}_{\mathrm{p}}\right)$ from adults to children.

When scaling $\mathrm{CL}_{\mathrm{p}}$ to children, the prediction error $(\mathrm{PE})$ is not sensitive to the allometric exponent in children above the age of 5 years, resulting in accurate $C_{\mathrm{p}}$ predictions with allometric scaling in this age range for drugs eliminated by glomerular filtration or for drugs undergoing hepatic metabolism when enzyme activity is close to adult values.

In children below the age of 5 years, the PE in scaled $\mathrm{CL}_{\mathrm{p}}$ becomes increasingly more sensitive to the allometric exponent, drug properties and maturation, leading to biased $\mathrm{CL}_{\mathrm{p}}$ predictions with allometric scaling. 


\section{Introduction}

Allometric scaling's first main domain of application was scaling of the basal metabolic rate between species, after which a series of investigations (principally in mammals) suggested that interspecies differences in the basal metabolic rate were best described by a bodyweight-based exponential relationship with an exponent close to 0.75 [1-7]. Several theories have been developed to support the existence of a universal allometric scaling exponent [8-11]; however, these theories have been criticized, and discrepancies between the theory and observations have been reported [12-18].

The use of the allometric equation was extended to the scaling of size-related changes in clearance between species [19] and thereafter to the scaling of clearance from adults to children [20]. While different universal values [1,21] for the allometric exponent have been proposed, a value of 0.75 is commonly applied in order to scale clearance from adults to children. While allometric scaling is applicable to both plasma and whole blood clearance, in this work we focus on allometric scaling of plasma clearance $\left(\mathrm{CL}_{\mathrm{p}}\right)$ using an exponent of 0.75 , as this is the most commonly used for clearance parameters. This scaling approach will be referred to as AS0.75 in this work. This approach is appealing because it is a simple and fast method to scale paediatric $\mathrm{CL}_{\mathrm{p}}$. However, this use of AS0.75 relies on two important implicit assumptions, i.e. the assumption of equivalence between basal metabolic rate and clearance, and the assumption of equivalence between inter- and intraspecies scaling. As illustrated in Fig. 1, for each of these assumptions separately, AS0.75 was found not to be supported by experimental data, challenging the belief of the strong theoretical and empirical basis of AS when applied in scaling paediatric clearance [22-31].

For the scaling of $\mathrm{CL}_{\mathrm{p}}$ in the paediatric population, AS0.75 has been recognized as a useful tool to extrapolate $\mathrm{CL}_{\mathrm{p}}$ from adult values to adolescents [32], while overpredictions in children younger than 5 years [33], reaching up to more than 200 and $3000 \%$ in infants and premature neonates, respectively, have been reported [34]. The latter is often attributed to the maturational process occurring simultaneously with growth at young ages [35], similar to what was concluded for the intraspecies scaling of the basal metabolic rate [22]. To cope with this, the estimation of a maturation function (MF) in addition to AS0.75 has been proposed [35]. Because of the high correlation between age and size, and consequently the difficulty in disentangling the influence of size-related changes from the influence of age-related changes, their distinction has hitherto been mainly driven by the AS0.75 theory, according to which all changes in $\mathrm{CL}_{\mathrm{p}}$ that are not accounted for by AS0.75 are due to maturation. Moreover, the accuracy of AS0.75 of $\mathrm{CL}_{\mathrm{p}}$ from adults to children has been evaluated for a limited number of drugs and it is unknown how the accuracy is impacted by various drug properties.

The aim of this study was to unravel in which situations AS0.75 consistently leads to accurate paediatric $\mathrm{CL}_{\mathrm{p}}$ predictions. To perform a systematic investigation, we developed a physiologically-based pharmacokinetic (PBPK) workflow for a wide range of hypothetical drugs cleared through hepatic metabolism or glomerular filtration (GF), and explored two scenarios-a scenario including size-related changes only, and a scenario including sizerelated changes as well as maturational changes. This methodology allowed for the disentanglement of the impact of drug properties, size-related changes, and maturation processes on the performance of AS0.75 in predicting paediatric $\mathrm{CL}_{\mathrm{p}}$ from adult values.

\section{Methods}

A PBPK simulation workflow was developed in $\mathrm{R}$ version 3.0.2 (Fig. 2). This workflow was used to investigate the accuracy of AS0.75 in predicting paediatric $\mathrm{CL}_{\mathrm{p}}$, simulated based on PBPK principles, for a total of 12,620 hypothetical drugs $(X)$.
Fig. 1 Implicit assumptions underlying the use of AS to scale $\mathrm{CL}_{\mathrm{p}}$ from adults to children. $A S$ allometric scaling, $C L_{p}$ plasma clearance

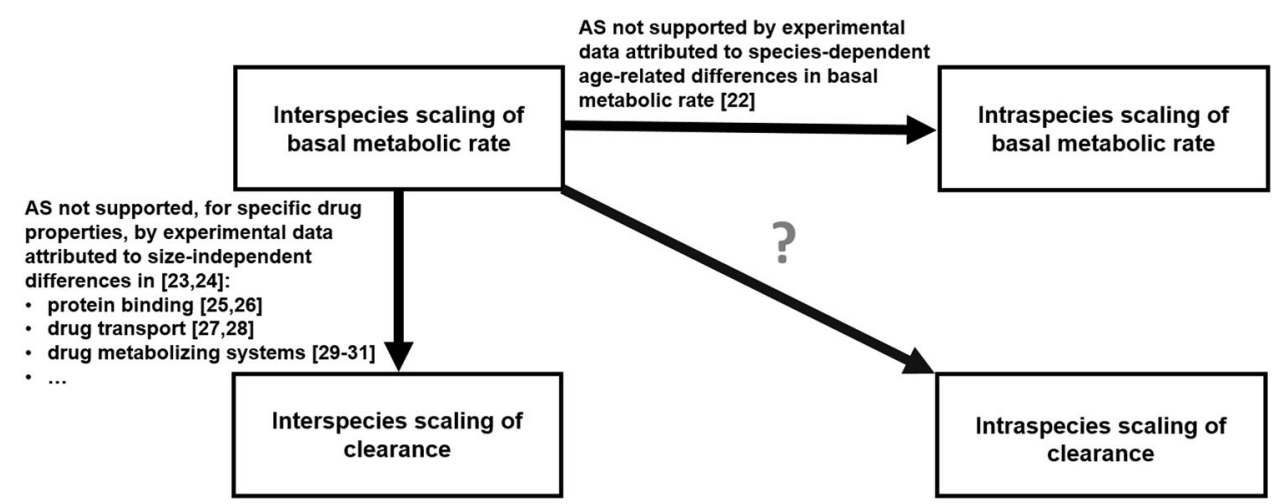




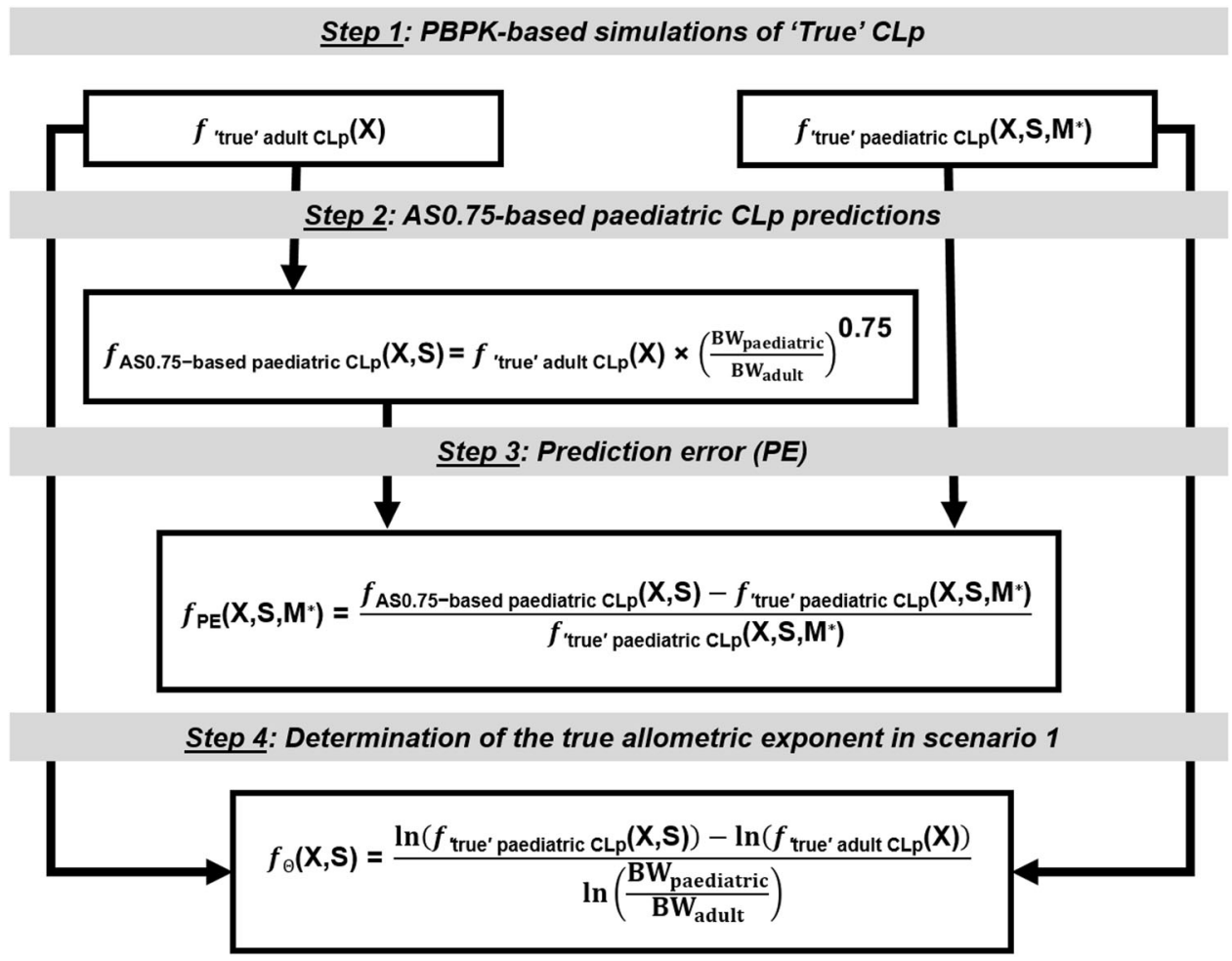

* Maturation $\mathrm{M}$ in function only applicable for scenario 2

Fig. 2 PBPK simulation workflow investigating the predictive performance of AS0.75 on the basis of bodyweight to the power of 0.75 , when scaling paediatric $\mathrm{CL}_{\mathrm{p}}$ from adult $\mathrm{CL}_{\mathrm{p}}$ values. The simulations include two scenarios: scenario 1 includes size-related changes only, while scenario 2 includes both size-related changes and maturation in the PBPK-based predictions of paediatric $\mathrm{CL}_{\mathrm{p}}$. Simulated $\mathrm{CL}_{\mathrm{p}}$ values are functions of $X$ representing drug-specific properties (i.e. $f_{\mathrm{u}}$, type of binding plasma protein, $\mathrm{CL}_{\mathrm{int} \text {,mic }}$, and $K_{\mathrm{p}}$ ). Paediatric $\mathrm{CL}_{\mathrm{p}}$ predictions

\subsection{Hypothetical Drugs $(X)$}

In the simulations, numerous different hypothetical drugs were investigated to explore the dependence of AS0.75 predictive performance on drug properties, as drug properties have been shown to influence the predictive performance of AS0.75 in interspecies scaling of clearance (see Fig. 1). Five drug-specific properties were used to generate a wide range of hypothetical drugs $(X)$; namely, route of elimination, type of binding plasma protein, affinity to the plasma protein, blood to plasma partition coefficient $\left(K_{\mathrm{p}}\right)$, and the unbound intrinsic clearance value of one microgram of liver microsomes $\left(\mathrm{CL}_{\mathrm{int}, \mathrm{mic}}\right)$. Thus, the design space was a five-dimensional hypercube, with each drug property corresponding to one dimension.

The two investigated routes of elimination were hepatic metabolism and GF. The hypothetical drugs were exclusively bound either to human serum albumin (HSA) or $\alpha 1$ acid glycoprotein (AGP). The affinity to plasma proteins were derived from the unbound drug fraction in plasma $\left(f_{\mathrm{u}}\right)$ also depend on $S$ representing size-related changes (changes in liver weight, hepatic blood flow, and glomerular filtration) and, in scenario 2, also on $M$, which represents maturational changes (changes in plasma protein concentration, haematocrit and $\mathrm{CL}_{\text {int,mic }}$ ). $P B P K$ physiologically-based pharmacokinetic, $C L_{p}$ plasma clearance, $f_{u}$ unbound drug fraction in plasma, $C L_{\text {int mic }}$ unbound microsomal intrinsic clearance, $K_{p}$ blood to plasma partition coefficient

in adults and the plasma concentration of the binding plasma protein in adults [36], using equations derived from Rodgers and Rowland [37]. The $f_{\mathrm{u}}$ in adults ranged from 1 to $100 \%$, with eight equidistant intermediate values. Because the $f_{\mathrm{u}}$ is more frequently reported than drug affinity to plasma protein, the $f_{\mathrm{u}}$ in adults, together with the type of binding plasma protein, was retained for drug categorization. $K_{\mathrm{p}}$ values of $0,1,2,3$ and 4 were selected, reflecting different extents of drug diffusion in the red blood cells. $\mathrm{CL}_{\text {int,mic }}$ ranged between $0.56 \times 10^{-3}$ and 0.209 $\mathrm{L} \mathrm{min}^{-1} \mathrm{mg}^{-1}$ microsomal protein [38], with 124 equidistant intermediate values. The different $\mathrm{CL}_{\text {int,mic }}$ values reflect different affinities for and abundances of enzymes.

Hypothetical drugs undergoing hepatic metabolism were generated based on all possible combinations of the aforementioned drug properties, while hypothetical drugs undergoing GF were generated by all possible combinations of affinity to plasma protein and type of binding plasma protein only, as $\mathrm{CL}_{\text {int,mic }}$ and $K_{\mathrm{p}}$ do not impact their clearance. 


\subsection{Simulation Scenarios}

Two different scenarios regarding maturation (scenario 1 and scenario 2) were included in the PBPK-based simulation workflow, and an overview of these scenarios is displayed in Table 1.

The first scenario (scenario 1) was designed in order to answer the question as to whether scaling using an allometric exponent of 0.75 accounts for all size-related changes in the processes underlying $\mathrm{CL}_{\mathrm{p}}$ in the paediatric population. Therefore, for this scenario, only size-related changes were included in the simulations of PBPK-based 'true' paediatric $\mathrm{CL}_{\mathrm{p}}$ values. Size-related changes $(S)$ included in the PBPK simulations are changes in liver weight, hepatic blood flow, and GF rate (GFR) [see step 1 of the PBPK simulation workflow for details on size-related changes]. In this scenario, for drugs undergoing hepatic metabolism, enzymes were considered to have reached maturity $\left(\mathrm{CL}_{\text {int,mic }}\right.$ was set to be $100 \%$ of the adult value). Furthermore, for this scenario, only drugs that do not bind to plasma proteins and which are in equilibrium between plasma and red blood cells $\left(K_{\mathrm{p}}\right.$ of 1$)$ were included in order to exclude the potential influence of maturational changes on $\mathrm{CL}_{\mathrm{p}}$ (see Eqs. 15 and 22-24 in the electronic supplementary material). This drug selection is equivalent to a selection of probe drugs for which only size-related changes would impact the clearance.

A second scenario (scenario 2) was designed to investigate how maturation processes influence the applicability of AS0.75 in the paediatric population, in order to unravel the conditions in which AS0.75 consistently leads to accurate paediatric $\mathrm{CL}_{\mathrm{p}}$ predictions. Therefore, for this scenario, size-related changes $(S)$ were included in the simulations of PBPK-based 'true' paediatric $\mathrm{CL}_{\mathrm{p}}$ values, as well as maturation processes $(M)$, which are believed not to be corrected for by AS0.75. Maturation processes included maturation in plasma protein concentration and haematocrit, as well as hepatic enzyme maturation (see step 1 of the PBPK simulation workflow for details on maturation). For this scenario, all hypothetical drugs were included.

\subsection{Physiologically-Based Pharmacokinetic (PBPK) Simulation Workflow}

\subsubsection{Step 1: PBPK-Based Simulations of 'True' Plasma Clearance $\left(C L_{p}\right)$}

For both scenarios, PBPK principles were used to simulate 'true' $\mathrm{CL}_{\mathrm{p}}$ values for the hypothetical drugs with different properties $(X$; see the 2.1 section) in term neonates aged 1 day, infants aged 1 and 6 months, children aged 1, 2, and 5 years, adolescents aged 15 years, and adults (Fig. 2). For drugs undergoing hepatic metabolism, $\mathrm{CL}_{\mathrm{p}}$ was computed using the dispersion model (Eqs. 1-6), with an axial dispersion number $\left(D_{\mathrm{N}}\right)$ of 0.17 [39]. The dispersion model was selected as it has been reported to better predict clearance than the well-stirred model for high-clearance drugs, which are also included in the hypothetical drugs, while both models lead to equivalent clearance predictions for the rest of the drugs [40]:

$$
\begin{aligned}
& \mathrm{CLp}=\mathrm{CL}_{\mathrm{B}} \times B: P \\
& \mathrm{CL}_{\mathrm{B}}=Q_{\mathrm{H}} \times E_{\mathrm{H}} \\
& E_{\mathrm{H}}=1-F_{\mathrm{H}} \\
& F_{\mathrm{H}}=\frac{4 a}{(1+a)^{2} \exp \left\{(a-1) / 2 D_{\mathrm{N}}\right\}-(1-a)^{2} \exp \left\{-(a+1) / 2 D_{\mathrm{N}}\right\}}
\end{aligned}
$$

\begin{tabular}{|c|c|c|}
\hline & Scenario 1 & Scenario 2 \\
\hline \multirow{2}{*}{$\begin{array}{l}\text { Aim and research } \\
\text { question }\end{array}$} & Investigation of AS0.75 theory & Investigation of general applicability of AS0.75 in paediatrics \\
\hline & $\begin{array}{l}\text { Does an allometric exponent of } 0.75 \text { account for size- } \\
\text { related changes in paediatric CLp? }\end{array}$ & $\begin{array}{l}\text { Under which conditions AS } 0.75 \text { consistently leads to accurate } \\
\text { paediatric CLp predictions? }\end{array}$ \\
\hline \multirow[t]{2}{*}{$\begin{array}{l}\text { PBPK-based } \\
\text { "true" CLp }\end{array}$} & $\begin{array}{l}\text { Only size-related changes }(S) \text { were included in the } \\
\text { PBPK simulations of true CLp }\end{array}$ & $\begin{array}{l}\text { Both size-related changes }(S) \text { and maturation }(M) \text { were included } \\
\text { in the PBPK simulations of true CLp }\end{array}$ \\
\hline & $\begin{array}{l}S \text { include changes in liver weight, hepatic blood flow, } \\
\text { and glomerular filtration rate }\end{array}$ & $\begin{array}{l}M \text { includes maturation in plasma protein concentration and in } \\
\text { haematocrit as well as hepatic enzyme maturation }\end{array}$ \\
\hline \multirow{8}{*}{$\begin{array}{l}\text { Selection of } \\
\text { hypothetical } \\
\text { drugs }\end{array}$} & Selection of hypothetical drugs equivalent to a selection & All hypothetical drugs \\
\hline & of probe drugs for which only size-related changes & The number drugs: \\
\hline & would impact the clearance, by retaining drugs with: & undergoing GF was 20 \\
\hline & $f_{\mathrm{u}}=1$ & undergoing hepatic metabolism was 12600 \\
\hline & $K_{\mathrm{p}}=1$ & \\
\hline & The number of selected drugs: & \\
\hline & undergoing GF was 1 & \\
\hline & undergoing hepatic metabolism was 126 & \\
\hline
\end{tabular}

Table 1 Overview of the two scenarios investigated in the PBPK-based simulation workflow. PBPK physiologically-based pharmacokinetic 
$a=\left(1+4 R_{\mathrm{N}} \times D_{\mathrm{N}}\right)^{1 / 2}$

$R_{\mathrm{N}}=\left(f_{\mathrm{u}} / B: P\right) \times \mathrm{CLint} / Q_{\mathrm{H}}$

In these equations, $\mathrm{CL}_{\mathrm{p}}$ is the plasma clearance, $B: P$ is the blood to plasma ratio, $\mathrm{CL}_{\mathrm{B}}$ is the whole blood clearance, $Q_{\mathrm{H}}$ is the hepatic blood flow, $E_{\mathrm{H}}$ is the hepatic extraction ratio, $f_{\mathrm{u}}$ is the unbound drug fraction in plasma, $\mathrm{CL}_{\mathrm{int}}$ is the hepatic intrinsic clearance, and $D_{\mathrm{N}}$ is the dispersion number. For drugs undergoing $\mathrm{GF}, \mathrm{CL}_{\mathrm{p}}$ was computed as the product of GFR [36] and $f_{\mathrm{u}}$.

Adult demographic values (height and weight) and adult values for cardiac output were taken from the ICRP annals [41]. $\mathrm{CL}_{\text {int }}$ in adults was computed as the product of $\mathrm{CL}_{\mathrm{int} \text {,mic }}$, amount of microsomal protein per gram of liver, and liver weight [36]. $B: P$ in adults was derived from the $K_{\mathrm{p}}$ value, adult haematocrit [42], and $f_{\mathrm{u}}$ in adults. $\mathrm{CL}_{\text {int,mic }}, K_{\mathrm{p}}$ and $f_{\mathrm{u}}$ in adults were taken from the values defined to generate the hypothetical drugs (see the 2.1 section).

Paediatric demographic values (height and weight) were taken from the CDC growth charts [43], and paediatric cardiac output values were compiled from Johnson et al. [36]. Size-related changes in $\mathrm{CL}_{\text {int }}$ were accounted for by changes in liver weight, and size-related changes in GF were accounted for by changes in GFR [36]. Maturation of $\mathrm{CL}_{\text {int }}$ was accounted for by selected extents of enzyme maturation [36]. For all hypothetical drugs undergoing hepatic metabolism, different extents of enzyme maturation, ranging between 10 and $200 \%$ of the adult $\mathrm{CL}_{\text {int,mic }}$ value, were investigated for each paediatric age. Additionally, scenarios were simulated with published enzyme maturation values for different hepatic isoenzymes [36, 44-47]. For these scenarios, values for enzyme maturation in neonates aged 1 day are based on values for term neonates. $F_{\mathrm{u}}$ was scaled from adults to children by accounting for maturation in plasma protein concentration (HSA and AGP) [36]. $B: P$ was scaled from adults to children by accounting for maturation in haematocrit [42] and plasma protein concentrations [36].

The 'true' $C_{p}$ s herein simulated are a function of the properties of the hypothetical drug $(X)$, size-related changes $(S)$, and, in scenario $2\left(^{*}\right)$, maturation $(M)$ : $f^{\prime}$ true' $\operatorname{CLp}(X, S, M *)$. In order to allow for computation across a wide parameter space and improve interpretability of the results, single-point estimates of $f^{\prime}$ true' $\operatorname{CLp}(X, S, M *)$ were studied by transforming $X, S$, and $M$ in categorical variables using typical values for the model parameters. For the same reasons, variability or uncertainty in demographic parameters or model parameters was not taken into account. Details on all equations used in the PBPK model and parameter values used in the simulations can be found in the electronic supplementary material.

\subsubsection{Step 2: AS0.75-Based Paediatric $C L_{p}$ Predictions}

In the AS0.75 equation (Fig. 2), bodyweight (BW) is used as a descriptor of size. AS0.75-based $\mathrm{CL}_{\mathrm{p}}$ predictions for children $[f \mathrm{AS} 0.75$ - based paediatric $\operatorname{CLp}(X, S)]$ were performed in both scenarios for all included combinations of hypothetical drugs $(X)$ and size-related changes $(S)$, using the AS0.75 relationship. For scenario 1, only drugs that do not bind to plasma proteins $\left(f_{\mathrm{u}}=1\right)$ and which are in equilibrium between plasma and red blood cells $\left(K_{\mathrm{p}}\right.$ of 1) were included in order to exclude the potential influence of maturational changes on $\mathrm{CL}_{\mathrm{p}}$ (see the 2.2 section, as well as Eqs. 15 and 22-24 in the electronic supplementary material).

In this AS0.75 relationship, the typical bodyweight for the different investigated paediatric ages (BWpaediatrics) was normalized to the bodyweight of a typical adult (BWadult). The typical bodyweight for the different paediatric ages and adults were kept the same as for the PBPK-based $\mathrm{CL}_{\mathrm{p}}$ simulations (see electronic supplementary material).

\subsubsection{Step 3: Prediction Error (PE)}

For both scenarios, the prediction error (PE) of AS0.75 using the fixed allometric exponent of 0.75 in predicting 'true' PBPK-based paediatric $\mathrm{CL}_{\mathrm{p}}$ was determined for all included combinations of hypothetical drugs $(X)$ and sizerelated changes $(S)$ [scenarios 1 and 2] and, where relevant, maturation $(M)$ [scenario 2]. For scenario 1, only drugs that do not bind to plasma proteins $\left(f_{\mathrm{u}}=1\right)$ and which are in equilibrium between plasma and red blood cells $\left(K_{\mathrm{p}}\right.$ of 1$)$ were included in order to exclude the potential influence of maturational changes on $\mathrm{CL}_{\mathrm{p}}$ (see the 2.2 section, as well as Eqs. 15 and 22-24 in the electronic supplementary material). Because this workflow relies on 'true' $\mathrm{CL}_{\mathrm{p}}$ predictions from simulations that do not take parameter uncertainty into account, predictions leading to PEs within an interval of $\pm 30 \%$ were considered accurate.

For both scenarios, results were categorized by age and route of elimination (hepatic metabolism or GF). For scenario 2 , in which both size-related changes and maturation were included, results were also categorized by type of binding plasma protein and extent of enzyme maturation. The $f_{\mathrm{u}}, K_{\mathrm{p}}, B: P$, and extraction ratio were screened for potential additional categorization.

\subsubsection{Step 4: Determination of the True Allometric Exponent in Scenario 1}

To investigate patterns in potential misspecification by AS0.75, which could be useful in deriving general rules regarding the applicability of AS0.75, the true allometric 
exponent $(\Theta)$ was derived for the scenario including only size-related changes (scenario 1); the true allometric exponent $\Theta$ was determined by rearranging the AS0.75 equation (Fig. 2). For each of the hypothetical drugs of this scenario, the PE obtained with AS0.75 was plotted against the true allometric exponent in order to evaluate the impact of the fixed 0.75 exponent instead of the true allometric exponent on the predictions accuracy.

\section{Results}

\subsection{Scenario 1}

Figure 3 shows the PE of AS0.75 in predicting 'true' paediatric $C L_{p}$ versus the true allometric exponent for each paediatric age for the scenario including size-related changes only (scenario 1) in the simulations of PBPKbased 'true' paediatric $\mathrm{CL}_{\mathrm{p}}$ values (see the 2.2 section). Figure $3 \mathrm{a}$ shows the results for 126 drugs undergoing hepatic metabolism only differing in their $\mathrm{CL}_{\text {int,mic }}$ values, and Fig. $3 b$ shows the results for one drug undergoing GF, as, for this scenario, only drugs that do not bind to plasma proteins $\left(f_{\mathrm{u}}=1\right)$ and which are in equilibrium between plasma and red blood cells $\left(K_{\mathrm{p}}\right.$ of 1$)$ were included in order to exclude the potential influence of maturational changes in these parameters on $\mathrm{CL}_{\mathrm{p}}$ (see the 2.1 and 2.2 sections, as well as Eqs. 15 and 22-24 in the electronic supplementary material). In this scenario, the true allometric exponent ranged from 0.52 to 0.88 for drugs undergoing hepatic metabolism, and from 0.50 to 1.20 for drugs undergoing GF. For both elimination routes, the true allometric exponent was higher in the youngest age groups. For drugs

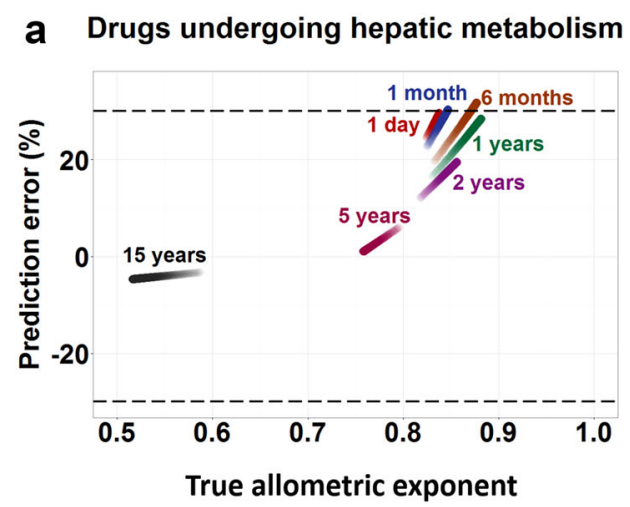

Fig. $3 \mathrm{PE}$ of AS0.75 using the fixed allometric exponent of 0.75 in predicting 'true' paediatric $\mathrm{CL}_{\mathrm{p}}$ versus the true allometric exponent for each paediatric age, for drugs undergoing (a) hepatic metabolism or (b) glomerular filtration in scenario 1, where only size-related changes were included in the PBPK-based simulations of 'true' paediatric $\mathrm{CL}_{\mathrm{p}}$. The values for the different ages are represented with undergoing hepatic metabolism, the true allometric exponent also slightly increased with decreasing $\mathrm{CL}_{\text {int,mic }}$ in children aged 5 years and older, with opposite results in children younger than 5 years of age.

The PE resulting from the use of the fixed allometric exponent of 0.75 instead of the true allometric exponent was higher in the youngest children. For drugs undergoing hepatic metabolism, PEs mostly remained within the $\pm 30 \%$ limits, with highest values reaching up to $32 \%$ in children aged 6 months. However, for drugs undergoing GF, PE was higher than $30 \%$ in children aged 6 months, and reached up to $278 \%$ in neonates aged 1 day. Moreover, the absolute $\mathrm{PE}$ increased with decreasing $\mathrm{CL}_{\text {int,mic }}$ in children aged 5 years and older, while it decreased with decreasing $\mathrm{CL}_{\text {int,mic }}$ in children younger than 5 years of age. For children aged 2 years and younger, drugs undergoing hepatic metabolism with similar true allometric exponents were found to lead to increased PE with decreasing age, showing a higher sensitivity of the PE to the use of a fixed allometric exponent of 0.75 in younger children.

\subsection{Scenario 2}

\subsubsection{PE for Hypothetical Drugs Undergoing Hepatic Metabolism}

Figure 4 shows the PE for the AS0.75-based paediatric $\mathrm{CL}_{\mathrm{p}}$ predictions in scenario 2 for drugs undergoing hepatic metabolism. Results are categorized by age, type of binding plasma protein, and extent of enzyme maturation. The extraction ratio in adults was found to be most predictive of the PE compared with $f_{\mathrm{u}}, K_{\mathrm{p}}$ or $B: P$. For this reason, results

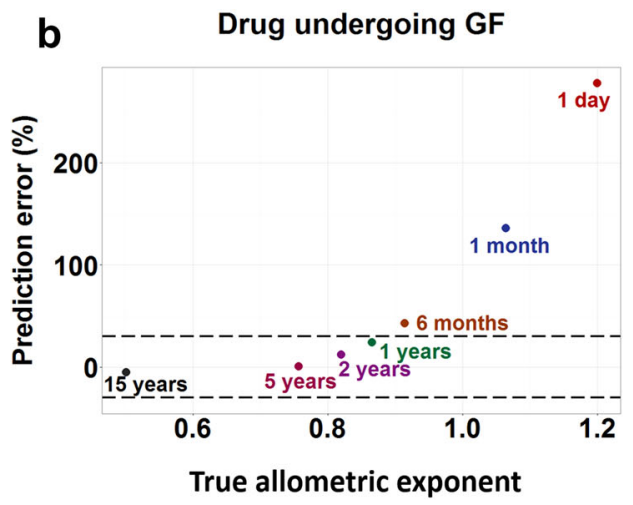

different colours. Colour intensity increases with $\mathrm{CL}_{\mathrm{int} \text {,mic }}$ values of the hypothetical drugs (a). Dotted black lines indicate a PE of $\pm 30 \%$. $P E$ prediction error, $C L_{p}$ plasma clearance, $P B P K$ physiologicallybased pharmacokinetic, $C L_{\text {int,mic }}$ unbound microsomal intrinsic clearance 
were also categorized by adult extraction ratio in boxplots, displaying the maximum, third quartile, median, first quartile and minimum PE for each category.

The PE range increased with decreasing age and was wider for drugs binding to AGP than for drugs binding to HSA. The more the enzyme maturation differed from $100 \%$ of the adult $\mathrm{CL}_{\text {int,mic }}$ value, the more the PE range increased, leading to the smallest PE range for enzyme maturation of $100 \%$. Enzyme maturation had less effect on the PE for high extraction ratio drugs compared with low extraction ratio drugs.

For drugs undergoing hepatic metabolism, AS0.75 led to accurate predictions for all hypothetical drugs in adolescents aged 15 years and children aged 5 years when $\mathrm{CL}_{\text {int,mic }}$ was between $75 \%$ and $100 \%$, and at $100 \%$ of the adult value, respectively. In a situation where $\mathrm{CL}_{\text {int,mic }}$ is at $100 \%$ of the adult value, 'true' $\mathrm{CL}_{\mathrm{p}}$ with a $\mathrm{PE}$ within $\pm 30 \%$ for all investigated ages is predicted only in cases of drugs with a low extraction ratio and binding to HSA. For the remaining drugs, the absolute $\mathrm{PE}$ ranged up to $50 \%$ in children as young as 6 months of age, and even higher in neonates. Regardless of age, ASO.75 performed poorly in predicting 'true' paediatric $\mathrm{CL}_{\mathrm{p}}$ of drugs metabolized by enzymes for which maturation is at or below $50 \%$ of the adult $\mathrm{CL}_{\text {int,mic }}$ value, leading to overprediction of more than $50 \%$ for a large part of the investigated hypothetical drugs.

Table 2 displays published $\mathrm{CL}_{\text {int,mic }}$ maturation values for hepatic isoenzymes for each paediatric age, together with their corresponding category of PE for AS0.75-based $\mathrm{CL}_{\mathrm{p}}$ predictions for all hypothetical drugs. Three PE categories were defined, with the PE range for all hypothetical drugs lying within $\pm 30 \%$ (green), within $\pm 50 \%$ (orange), and including absolute PE values higher than $50 \%$ (red), with PE values rounded to the tenth (i.e $32 \%$ was rounded to $30 \%$ ). The PE of AS0.75-based $\mathrm{CL}_{\mathrm{p}}$ predictions for all hypothetical drugs was within $\pm 30 \%$ in children aged 5 years and older, except for one of the three cytochrome P450 (CYP) 1A2 enzyme maturation patterns and one of the two CYP2E1 enzyme maturation patterns published in children aged 5 years. For neonates aged 1 day and infants aged 1 month, the PE range systematically included absolute values $>50 \%$ for hypothetical substrates of all isoenzymes. Intermediate results were found for children between 6 months and 2 years of age.

\subsubsection{PE for Hypothetical Drugs Undergoing Glomerular Filtration}

Table 3 displays the PE of AS0.75-based $\mathrm{CL}_{\mathrm{p}}$ predictions for each paediatric age and each hypothetical drug undergoing GF. Drugs undergoing GF only differed by their $f_{\mathrm{u}}$ and type of binding plasma protein. AS0.75 led to a PE within $\pm 30 \%$ for all these drugs in children as young as 1 year of age, with the exception of those drugs highly bound to AGP (adult $f_{\mathrm{u}} \leq 0.12 \%$ ) in children aged 1 and 2 years. AS0.75 predictions in neonates aged 1 day and infants aged 1 month led to a PE of up to more than $100 \%$.

Figure 5 displays a summary of the results regarding the applicability of AS0.75 to scale $\mathrm{CL}_{\mathrm{p}}$ from adults to children. Scenarios for which AS0.75 led to accurate $\mathrm{CL}_{\mathrm{p}}$ predictions were defined, including ages, enzyme maturation and drug properties.

\section{Discussion}

In this study, a PBPK simulation workflow was developed in order to systematically investigate, for the first time, the accuracy of AS0.75-based paediatric $\mathrm{CL}_{\mathrm{p}}$ predictions for a wide range of hypothetical drugs, undergoing hepatic metabolism or GF. The use of a systematic approach increases our current knowledge on the applicability of AS0.75 to predict paediatric $\mathrm{CL}_{\mathrm{p}}$ based on adult values, which has, until now, been based on studies of a limited number of existing drugs and a limited number of observed concentrations. The use of PBPK principles allowed for the screening of the impact of size-related changes, maturation, and drug properties on the accuracy of ASO.75-based paediatric $\mathrm{CL}_{\mathrm{p}}$ predictions, which is not possible with other methods. This allowed us to define scenarios, including ages, drug properties (including elimination pathways), and maturation, for which AS0.75 is likely to lead to accurate paediatric $\mathrm{CL}_{\mathrm{p}}$ predictions (Fig. 5).

In contrast with previously proposed applications of AS0.75 theory in the paediatric population [20], but in line with more recent work [18], the current study shows that there is no universal allometric exponent that can be used to accurately scale size-related changes in $\mathrm{CL}_{\mathrm{p}}$ from adults to children of various ages. Even when estimated in scenarios in which only size-related changes are included (scenario 1), the allometric exponent was found to vary from 0.50 to 1.20 , changing with age and drug properties (Fig. 3). The corresponding PE was found to be more sensitive to the use of a fixed exponent of 0.75 among the youngest children, leading to increased bias in very young children, with values around $30 \%$ for drugs undergoing hepatic metabolism and up to $278 \%$ for drugs undergoing GF (Fig. 3).

The inaccurate paediatric $\mathrm{CL}_{\mathrm{p}}$ predictions resulting from AS0.75 in the very young are often attributed to the influence of the many maturation processes that are known to occur in these children. Therefore, in model building, AS0.75 is usually used in combination with an MF that should account for these maturational changes, to describe $\mathrm{CL}_{\mathrm{p}}$ in this population for a specific drug. However, in 

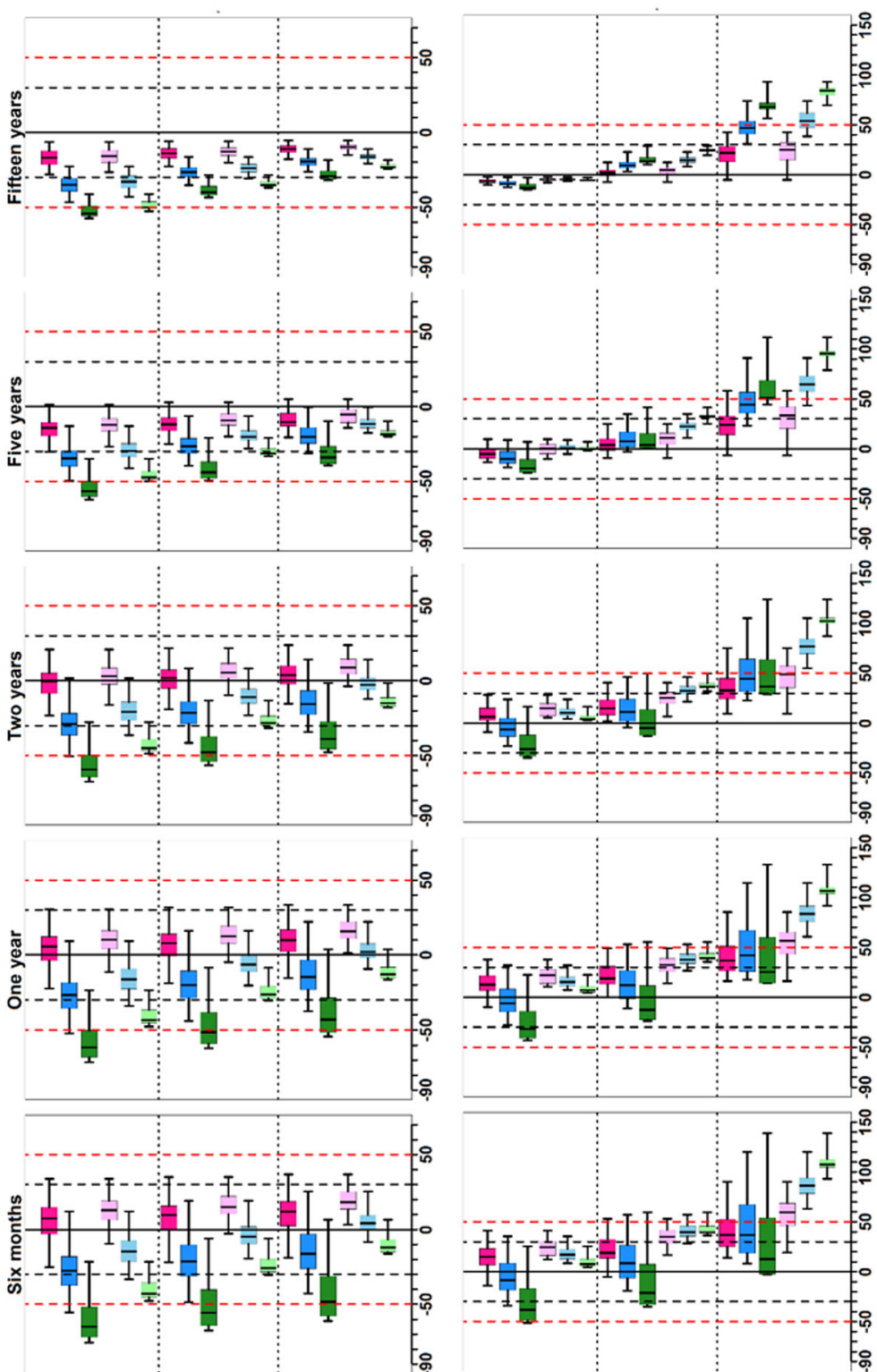

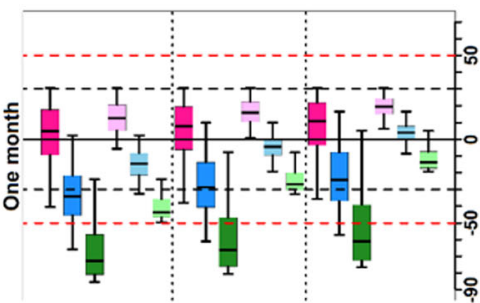

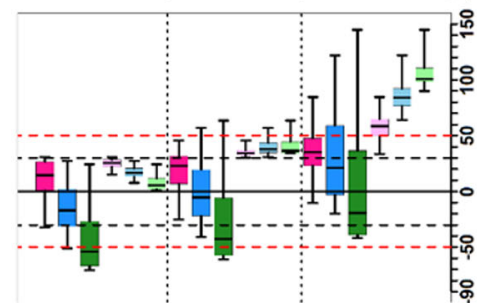

c:

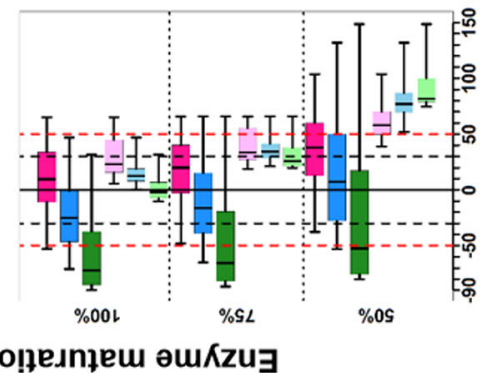

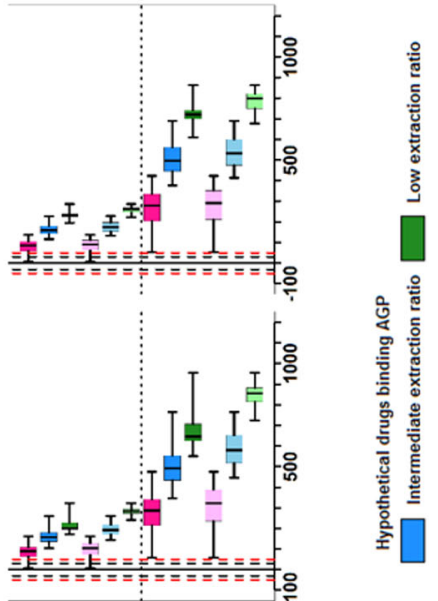
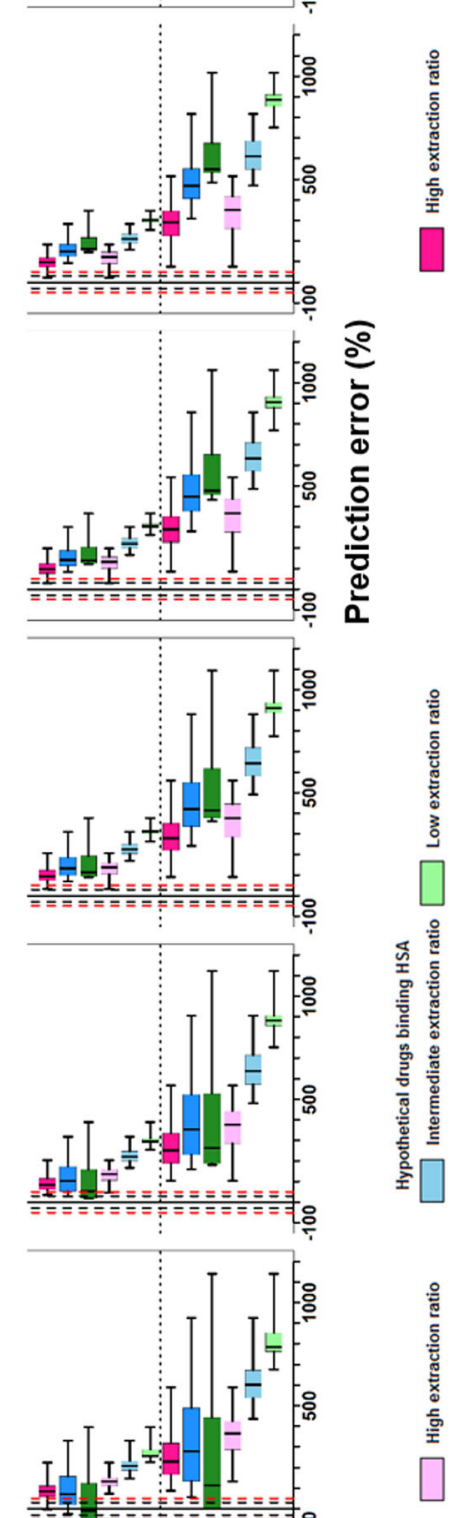
४Fig. 4 PE for AS0.75-based $\mathrm{CL}_{\mathrm{p}}$ predictions of drugs undergoing hepatic metabolism in scenario 2 , where both size-related changes and maturation were included in the simulations of 'true' paediatric $\mathrm{CL}_{\mathrm{p}}$, with enzyme maturation in $\mathrm{CL}_{\text {int,mic }}$ ranging from 10 to $200 \%$ of the adult value. $P E$ prediction error, $C L_{p}$ plasma clearance, $C L_{\text {int, mic }}$ unbound microsomal intrinsic clearance

scenario 1, which did not include maturation in the PBPKbased simulations of 'true' paediatric $\mathrm{CL}_{\mathrm{p}}$, the $\mathrm{PE}$ of the AS0.75-based $\mathrm{CL}_{\mathrm{p}}$ predictions was still large in children aged 6 months and younger (ranging from 43 to $278 \%$ ) for drugs undergoing GF. From this it can be concluded that in these scenarios, when modelling $\mathrm{CL}_{\mathrm{p}}$ in very young children using AS0.75 in combination with MF, the MF likely also corrects for bias introduced by the use of a fixed allometric exponent of 0.75 . Therefore, while the use of AS0.75 + MF may prove to be a viable method in some cases, there is no sufficient evidence to support its scientific basis, either for predicting drug clearance between individuals of different ages or for covariate relationships in model-building procedures. Moreover, there are no grounds to reject the well-established data-driven (i.e. stepwise covariate model building) strategies for the inclusion of bodyweight in a paediatric pharmacokinetic model, which have recently been used to develop more flexible functions to accurately scale $\mathrm{CL}_{\mathrm{p}}$ across the entire paediatric age range using only bodyweight in model development [48-51].

As similarly reported for interspecies AS0.75 of $\mathrm{CL}_{\mathrm{p}}$ [23-31] (Fig. 1), drug properties were found to impact the accuracy of the predictions (Figs. 3 and 4). While drug properties not amenable to AS0.75 could be defined in the case of interspecies AS0.75 of $\mathrm{CL}_{\mathrm{p}}[23,24]$, no unique trends (in terms of direction and extent) in the impact of drug properties on the PE were observed for AS0.75 of $\mathrm{CL}_{\mathrm{p}}$ in paediatric patients as this impact varied with maturation and size (Table 3 and Fig. 4).

We found that enzyme activity close to adult values is a requirement for accurate AS0.75-based $\mathrm{CL}_{\mathrm{p}}$ predictions at all paediatric ages, which is in agreement with previous reports [44, 52]. However, mature enzyme activity alone is not sufficient to lead to accurate AS0.75-based $\mathrm{CL}_{\mathrm{p}}$ predictions, as, in children younger than 5 years, AS0.75 can lead to a $\mathrm{PE}>30 \%$, depending on the drug properties, even when enzyme activity is close to adult values (Fig. 4). With the exception of certain publications on CYP2E1 and CYP1A2, it is commonly believed that hepatic enzymes are mature in children aged 5 years and older (Table 2), which is in line with previous reports on the use of AS0.75 to predict $\mathrm{CL}_{\mathrm{p}}$ in children older than 5 years of age $[34,53]$.

Table 2 Published enzyme maturation values and their corresponding PE category of AS0.75-based $\mathrm{CL}_{\mathrm{p}}$ predictions for drugs undergoing hepatic metabolism for scenario 2

\begin{tabular}{|c|c|c|c|c|c|c|c|}
\hline CYP1A2 [36] & 0.022 & 3 & 25 & 47 & 70 & 90 & 98 \\
\hline CYP1A2 [44] & 5 & 20 & 29 & 35 & NA & NA & 100 \\
\hline CYP1A2 [45] & 27 & 41 & 122 & 153 & 159 & 152 & 123 \\
\hline CYP2B6 [36] & 0.22 & 6 & 30 & 46 & 65 & 85 & 98 \\
\hline СYP2C8 [36] & 39 & 88 & 99 & 100 & 101 & 101 & 102 \\
\hline CYP2C9 [36]- & 39 & 94 & 101 & 102 & 103 & 103 & 103 \\
\hline CYP2C18_19 [36] & 23 & 30 & 52 & 66 & 80 & 95 & 103 \\
\hline CYP2D6 [36]- & 6 & 49 & 88 & 95 & 100 & 103 & 104 \\
\hline CYP2E1 [36] ${ }^{-}$ & 11 & 26 & 41 & 49 & 57 & 71 & 90 \\
\hline CYP2E1 [44] & 21 & 40 & 46 & 100 & $100^{*}$ & $100^{\star}$ & 100 \\
\hline CYP3A4 [44] & 20 & 50 & 110 & 130 & 130 & NA & 100 \\
\hline CYP3A4 [46] & 10 & NA & 43 & 54 & 72 & 101 & 100 \\
\hline CYP3A4_5 [36]- & 2 & 29 & 64 & 76 & 85 & 92 & 97 \\
\hline UGT2B7 [44] & 5 & 10 & 70 & 100 & $100^{*}$ & $100^{*}$ & 100 \\
\hline UGT1A6 [44]- & 10 & 16 & 36 & 50 & NA & NA & 100 \\
\hline SULT1A1 [47]- & 100 & 100 & 100 & 100 & 100 & 100 & 100 \\
\hline & One day & One month & Six months & One year & Two years & Five years & Fifteen years \\
\hline
\end{tabular}

Numbers within cells correspond to the value of enzyme maturation, as a percentage of adult enzyme activity, for each age and isoenzyme. NA was used when no data on enzyme maturation for the corresponding age and isoenzyme were reported. * Indicates replacement of missing enzyme maturation values (NA) by $100 \%$ when reported values in younger and older children were equal to $100 \%$. Colours indicate the PE category, with PE range for all hypothetical drugs lying within $\pm 30 \%$ in green, within $\pm 50 \%$ in orange, and including absolute values higher than $50 \%$ in red. PE values were rounded to the tenth. $P E$ prediction error, $C L_{p}$ plasma clearance 
Table 3 PE for AS0.75-based $\mathrm{CL}_{\mathrm{p}}$ predictions for each drug binding to AGP or HSA and undergoing glomerular filtration in scenario 2, where both sizerelated changes and maturation were included in the simulations of 'true' paediatric $\mathrm{CL}_{\mathrm{p}}$. Colours indicate the prediction error categories for each drug. Three prediction error categories were defined, with PE lying within $\pm 30 \%$ in green, within $\pm 50 \%$ in orange, and including absolute values higher than $50 \%$ in red. $P E$ prediction error, $C L_{p}$ plasma clearance, $A G P \propto 1$-acid glycoprotein, $H S A$ human serum albumin

\begin{tabular}{|c|c|c|c|c|c|c|c|c|}
\hline $\begin{array}{c}\text { Adult } \\
\text { fu }\end{array}$ & $\begin{array}{c}\text { Binding } \\
\text { protein }\end{array}$ & $\begin{array}{c}\text { One } \\
\text { day }\end{array}$ & $\begin{array}{c}\text { One } \\
\text { month }\end{array}$ & $\begin{array}{c}\text { Six } \\
\text { months }\end{array}$ & $\begin{array}{c}\text { One } \\
\text { year }\end{array}$ & $\begin{array}{c}\text { Two } \\
\text { years }\end{array}$ & $\begin{array}{c}\text { Five } \\
\text { years }\end{array}$ & $\begin{array}{c}\text { Fifteen } \\
\text { years }\end{array}$ \\
\hline \multirow{2}{*}{0.01} & AGP & -70 & -44 & -42 & -39 & -35 & -28 & -17 \\
\cline { 2 - 9 } & HSA & 172 & 94 & 25 & 11 & 3 & -5 & -7 \\
\hline \multirow{2}{*}{0.12} & AGP & -31 & -24 & -33 & -32 & -29 & -25 & -15 \\
\cline { 2 - 9 } & HSA & 184 & 99 & 27 & 13 & 4 & -4 & -7 \\
\hline \multirow{2}{*}{0.23} & AGP & 7 & -4 & -23 & -25 & -24 & -22 & -14 \\
\cline { 2 - 9 } & HSA & 196 & 103 & 29 & 14 & 5 & -4 & -7 \\
\hline \multirow{2}{*}{0.34} & AGP & 46 & 16 & -14 & -18 & -19 & -18 & -13 \\
\cline { 2 - 9 } & HSA & 207 & 108 & 31 & 16 & 6 & -3 & -7 \\
\hline \multirow{2}{*}{0.45} & AGP & 85 & 36 & -4 & -11 & -14 & -15 & -11 \\
\cline { 2 - 9 } & HSA & 219 & 113 & 33 & 17 & 7 & -2 & -6 \\
\hline \multirow{2}{*}{0.56} & AGP & 123 & 56 & 5 & -4 & -8 & -12 & -10 \\
\cline { 2 - 9 } & HSA & 231 & 117 & 35 & 19 & 8 & -2 & -6 \\
\hline \multirow{2}{*}{0.67} & AGP & 162 & 76 & 15 & 3 & -3 & -9 & -9 \\
\cline { 2 - 9 } & HSA & 243 & 122 & 37 & 20 & 9 & -1 & -6 \\
\hline \multirow{2}{*}{0.78} & AGP & 201 & 96 & 24 & 10 & 2 & -6 & -8 \\
\cline { 2 - 9 } & HSA & 255 & 127 & 39 & 22 & 10 & 0 & -5 \\
\hline \multirow{2}{*}{0.89} & AGP & 239 & 116 & 33 & 18 & 7 & -2 & -6 \\
\cline { 2 - 9 } & HSA & 266 & 131 & 41 & 23 & 11 & 0 & -5 \\
\hline \multirow{2}{*}{1} & AGP & 278 & 136 & 43 & 25 & 13 & 1 & -5 \\
\cline { 2 - 8 } & HSA & 278 & 136 & 43 & 25 & 13 & 1 & -5 \\
\hline
\end{tabular}

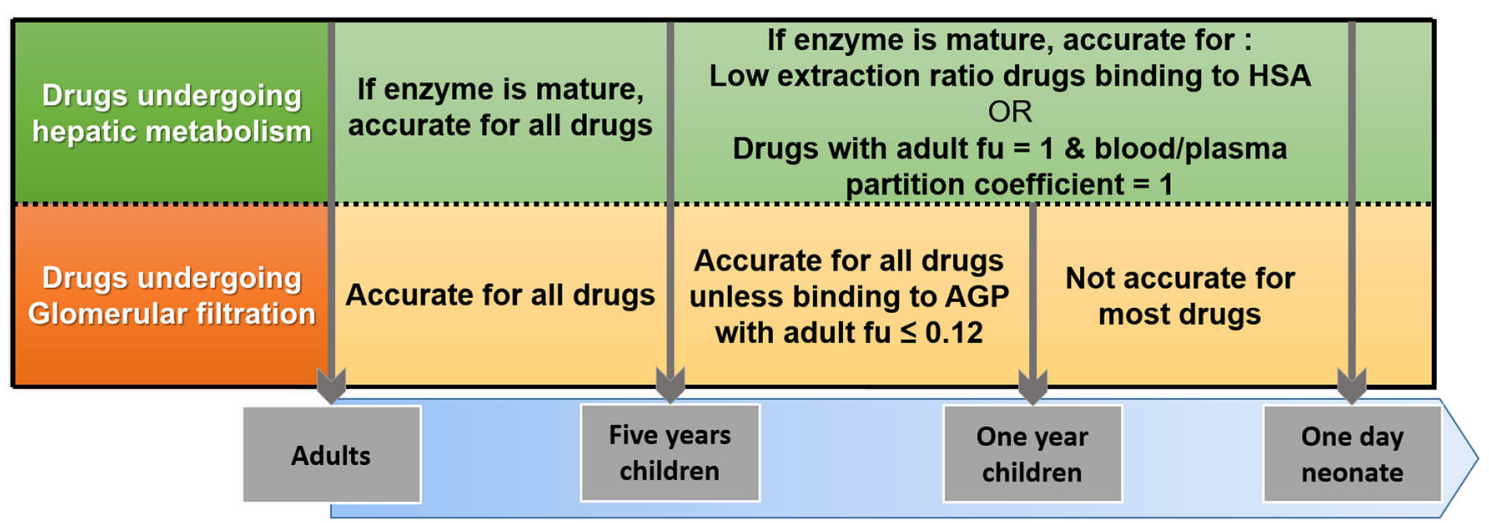

Fig. 5 Scenarios for which AS0.75-based paediatric $\mathrm{CL}_{\mathrm{p}}$ predictions are accurate, based on a PBPK simulation workflow. $C L_{p}$ plasma clearance, $P B P K$ physiologically-based pharmacokinetic

Drugs undergoing GF were found to be amenable to AS0.75 of $\mathrm{CL}_{\mathrm{p}}$ until a younger age, than drugs undergoing hepatic metabolism. Our results show that clearance through GF can be accurately predicted in children as young as 1 year of age for all drugs, with the exception of drugs highly bound to AGP $\left(f_{\mathrm{u}} \leq 0.12\right)$ in children aged between 1 and 5 years. While this result seems in line with previous findings that GFR reaches adult values at $8-12$ months of age [54], we emphasize that secretion and reabsorption processes are not yet included in the simulations.
Sethi et al. [55] recently suggested that the $f_{\mathrm{u}}$ for drugs binding to albumin was smaller than what can be predicted using MFs for albumin currently in use, in children younger than 4 years of age. The underestimated $f_{\mathrm{u}}$ in children would impact the results but would not impact our conclusion. Indeed, for children aged 3 months and younger, we found that AS0.75 led to inaccurate $\mathrm{CL}_{\mathrm{p}}$ prediction for drugs undergoing both hepatic metabolism and GF.

The use of a PBPK approach allowed for the disentanglement of size-related changes, drug properties, and maturation processes due to its unique feature to 
incorporate multiple levels of information to predict $\mathrm{CL}_{\mathrm{p}}$ for different paediatric ages. Over the past decade, the scaling of an adult PBPK model to paediatric patients has been proven to lead to accurate $\mathrm{CL}_{\mathrm{p}}$ predictions in children $[36,46,56,57]$. The investigation of hypothetical drugs in the current study allowed the avoidance of bias in PBPKbased $\mathrm{CL}_{\mathrm{p}}$ predictions due to the inaccurate measurements of drug-specific parameters, such as $f_{\mathrm{u}}$, which can occur when studying existing drugs [58]. The parameters defining drug properties should be interpreted as apparent parameters. For instance, a drug with a $K_{\mathrm{p}}$ of 0 could translate into a drug that can enter membranes and red blood cells, but for which distribution in red blood cells is not a limiting factor for its metabolism in the hepatocytes (i.e. fast drug repartitioning compared with the residence time of blood in the capillaries [59]). This simulation workflow does not account for illness, and different results might be expected in patients for whom physiological changes, for instance in AGP concentration or organ function, can impact the drug clearance [60]. However, this allows for the investigation of AS0.75 predictive performance without confounding factors such as illness, sparse paediatric clinical data, or bias in the estimation of adult $\mathrm{CL}_{\mathrm{p}}$ used in the AS0.75based paediatric $\mathrm{CL}_{\mathrm{p}}$ predictions.

The herein applied workflow is intended to give an overview of the impact of drug properties (including elimination pathways), size-related changes, and maturation on the accuracy of AS0.75-based $\mathrm{CL}_{\mathrm{p}}$ predictions. To do so, unrealistic enzyme maturation scenarios for part of the paediatric ages, as well as uniform distribution of drug properties (equidistant values), were included in the simulations using a global sensitivity analysis with a fractional design. Indeed, keeping enzyme maturation scenarios the same for different ages allows to differentiate between the impact of age and enzyme maturation, thereby unraveling an increased sensitivity of the accuracy of AS0.75-based CLp predictions to enzyme maturation with decreasing age (see Fig. 4). Therefore, the poor predictive performance of AS0.75 in young children is not solely due to enzyme immaturity in itself, but also due to an increased sensitivity of drug clearance to enzyme maturation at that age. Because this study was intended to be systematic and not probabilistic, results were not weighted on the likelihood of the investigated drug properties. This approach can be considered a risk assessment, where rare drug properties are considered as important as frequent drug properties.

\section{Conclusions}

Based on current PBPK knowledge, we found no evidence for a universal allometric exponent for scaling $\mathrm{CL}_{\mathrm{p}}$ in children. This finding holds even when only size-related changes are considered and maturation of processes underlying drug clearance are not taken into account. This work reveals that AS0.75 accurately predicts $\mathrm{CL}_{\mathrm{p}}$ in children over 5 years of age for drugs eliminated by GF and/or undergoing hepatic metabolism, when enzyme activity is close to adult values, due to the lack of sensitivity of PE to the allometric exponent and to the drug properties in this scenario.

\section{Compliance with Ethical Standards}

Funding This study was supported by a NOW/Vidi grant to Catherijne A. J. Knibbe (2013).

Conflict of interest Amin Rostami-Hodjegan is an employee of the University of Manchester, seconded part-time to Simcyp Limited (a Certara company) whose research is funded by a consortium of pharmaceutical companies.

Open Access This article is distributed under the terms of the Creative Commons Attribution-NonCommercial 4.0 International License (http://creativecommons.org/licenses/by-nc/4.0/), which permits any noncommercial use, distribution, and reproduction in any medium, provided you give appropriate credit to the original author(s) and the source, provide a link to the Creative Commons license, and indicate if changes were made.

\section{References}

1. Kleiber M. The fire of life: an introduction to animal energetics. New York: Wiley; 1961.

2. Kleiber M. Body size and metabolic rate. Physiol Rev. 1947;27(4):511-41.

3. Benedict FG. Vital energetics: a study in comparative basal metabolism. Washington, DC: Carnegie Institution; 1938.

4. Kleiber M. Body size and metabolism. Hilgardia. 1932;6:315-53.

5. Brody S. Bioenergetics and growth, with special reference to the efficiency complex in domestic animals. 1st ed. New York: Rienhold Publishing Corporation; 1945.

6. Hemmingsen AM. The relation of standard (basal) energy metabolism to total fresh weight of living organisms. Rep Steno Mem Hosp Nordisk Insulin Lab. 1950;4:1-48.

7. Hemmingsen AM. Energy metabolism as related to body size and respiratory surfaces, and its evolution. Rep Steno Mem Hosp Nordisk Insulin Lab. 1960;9:1-110.

8. West GB, Brown JH, Enquist BJ. A general model for the origin of allometric scaling laws in biology. Science. 1997;276(5309):122-6.

9. McMahon T. Size and shape in biology. Science. 1973;179(4079):1201-4.

10. Banavar JR, Damuth J, Maritan A, Rinaldo A. Supply-demand balance and metabolic scaling. Proc Natl Acad Sci USA. 2002;99(16):10506-9.

11. West GB, Brown JH, Enquist BJ. The fourth dimension of life: fractal geometry and allometric scaling of organisms. Science. 1999;284(5420):1677-9.

12. Glazier DS. Beyond the '3/4-power law': variation in the intraand interspecific scaling of metabolic rate in animals. Biol Rev Camb Philos Soc. 2005;80(4):611-62.

13. White CR, Cassey P, Blackburn TM. Allometric exponents do not support a universal metabolic allometry. Ecology. 2007;88(2):315-23. 
14. Packard GC, Birchard GF. Traditional allometric analysis fails to provide a valid predictive model for mammalian metabolic rates. J Exp Biol. 2008;211(Pt 22):3581-7.

15. Kolokotrones T, Van S, Deeds EJ, Fontana W. Curvature in metabolic scaling. Nature. 2010;464(7289):753-6.

16. Agutter PS, Wheatley DN. Metabolic scaling: consensus or controversy? Theor Biol Med Model. 2004;1:13.

17. Glazier DS. Metabolic scaling in complex living systems. Systems. 2014;2(4):451-540.

18. Mahmood I. Theoretical versus empirical allometry: facts behind theories and application to pharmacokinetics. J Pharm Sci. 2010;99(7):2927-33.

19. Weiss M, Sziegoleit W, Forster W. Dependence of pharmacokinetic parameters on the body weight. Int J Clin Pharmacol Biopharm. 1977;15(12):572-5.

20. Anderson BJ, McKee AD, Holford NH. Size, myths and the clinical pharmacokinetics of analgesia in paediatric patients. Clin Pharmacokinet. 1997;33(5):313-27.

21. Heusner AA. Energy metabolism and body size: I. Is the 0.75 mass exponent of Kleiber's equation a statistical artifact? Respir Physiol. 1982;48(1):1-12.

22. Kleiber M. Energy metabolism. Annu Rev Physiol. 1944;6(1):123-54.

23. Riviere JE, Martin-Jimenez T, Sundlof SF, Craigmill AL. Interspecies allometric analysis of the comparative pharmacokinetics of 44 drugs across veterinary and laboratory animal species. J Vet Pharmacol Ther. 1997;20(6):453-63.

24. Sharma V, McNeill JH. To scale or not to scale: the principles of dose extrapolation. Br J Pharmacol. 2009;157(6):907-21.

25. Callan WM, Sunderman FW Jr. Species variations in binding of 63 NI(II) by serum albumin. Res Commun Chem Pathol Pharmacol. 1973;5(2):459-72.

26. Tang H, Mayersohn M. A novel model for prediction of human drug clearance by allometric scaling. Drug Metab Dispos. 2005;33(9):1297-303.

27. Bleasby K, Castle JC, Roberts CJ, Cheng C, Bailey WJ, Sina JF, et al. Expression profiles of 50 xenobiotic transporter genes in humans and pre-clinical species: a resource for investigations into drug disposition. Xenobiotica. 2006;36(10-11):963-88.

28. Nozaki Y, Kusuhara H, Kondo T, Iwaki M, Shiroyanagi Y, Nakayama $\mathrm{H}$, et al. Species difference in the inhibitory effect of nonsteroidal anti-inflammatory drugs on the uptake of methotrexate by human kidney slices. J Pharmacol Exp Ther. 2007;322(3):1162-70.

29. Paine AJ. Heterogeneity of cytochrome P450 and its toxicological significance. Hum Exp Toxicol. 1995;14(1):1-7.

30. Resetar A, Spector T. Glucuronidation of $3^{\prime}$-azido- $3^{\prime}$-deoxythymidine: human and rat enzyme specificity. Biochem Pharmacol. 1989;38(9):1389-93.

31. Van Miert AS. Extrapolation of pharmacological and toxicological data based on metabolic weight. Arch Exp Veterinarmed. 1989;43(4):481-8.

32. Momper JD, Mulugeta Y, Green DJ, Karesh A, Krudys KM, Sachs HC, et al. Adolescent dosing and labeling since the Food and Drug Administration Amendments Act of 2007. JAMA Pediatr. 2013;167(10):926-32.

33. Mahmood I, Staschen CM, Goteti K. Prediction of drug clearance in children: an evaluation of the predictive performance of several models. AAPS J. 2014;16(6):1334-43.

34. Mahmood I. Prediction of drug clearance in children from adults: a comparison of several allometric methods. Br J Clin Pharmacol. 2006;61(5):545-57.

35. Anderson BJ, Allegaert K, Holford NH. Population clinical pharmacology of children: modelling covariate effects. Eur J Pediatr. 2006;165(12):819-29.
36. Johnson TN, Rostami-Hodjegan A, Tucker GT. Prediction of the clearance of eleven drugs and associated variability in neonates, infants and children. Clin Pharmacokinet. 2006;45(9):931-56.

37. Rodgers T, Rowland M. Physiologically based pharmacokinetic modelling 2: predicting the tissue distribution of acids, very weak bases, neutrals and zwitterions. J Pharm Sci. 2006;95(6): $1238-57$.

38. Nikolic K, Agababa D. Prediction of hepatic microsomal intrinsic clearance and human clearance values for drugs. J Mol Graph Model. 2009;28(3):245-52.

39. Naritomi Y, Terashita S, Kimura S, Suzuki A, Kagayama A, Sugiyama Y. Prediction of human hepatic clearance from in vivo animal experiments and in vitro metabolic studies with liver microsomes from animals and humans. Drug Metab Dispos. 2001;29(10):1316-24.

40. Ridgway D, Tuszynski JA, Tam YK. Reassessing models of hepatic extraction. J Biol Phys. 2003;29(1):1-21.

41. ICRP. Basic anatomical and physiological data for use in radiological protection: reference values. A report of age- and genderrelated differences in the anatomical and physiological characteristics of reference individuals. ICRP Publication 89. Ann ICRP. 2002;32(3-4):5-265.

42. Irwin JJ, Kirchner JT. Anemia in children. Am Fam Phys. 2001;64(8):1379-86.

43. Centers for Disease Control and Prevention NCHS. Length-forage and weight-for-age percentiles. Atlanta: Centers for Disease Control and Prevention; 2000.

44. Edginton AN, Schmitt W, Voith B, Willmann S. A mechanistic approach for the scaling of clearance in children. Clin Pharmacokinet. 2006;45(7):683-704

45. Salem F, Johnson TN, Abduljalil K, Tucker GT, Rostami-Hodjegan A. A re-evaluation and validation of ontogeny functions for cytochrome P450 1A2 and 3A4 based on in vivo data. Clin Pharmacokinet. 2014;53(7):625-36.

46. Bjorkman S. Prediction of drug disposition in infants and children by means of physiologically based pharmacokinetic (PBPK) modelling: theophylline and midazolam as model drugs. Br J Clin Pharmacol. 2005;59(6):691-704.

47. Hines RN. The ontogeny of drug metabolism enzymes and implications for adverse drug events. Pharmacol Ther. 2008;118(2):250-67.

48. Wang C, Peeters MY, Allegaert K, Blusse van Oud-Alblas HJ, Krekels EH, Tibboel D, et al. A bodyweight-dependent allometric exponent for scaling clearance across the human life-span. Pharm Res. 2012;29(6):1570-81.

49. Bartelink IH, Boelens JJ, Bredius RG, Egberts AC, Wang C, Bierings MB, et al. Body weight-dependent pharmacokinetics of busulfan in paediatric haematopoietic stem cell transplantation patients: towards individualized dosing. Clin Pharmacokinet. 2012;51(5):331-45.

50. Wang C, Allegaert K, Peeters MY, Tibboel D, Danhof M, Knibbe CA. The allometric exponent for scaling clearance varies with age: a study on seven propofol datasets ranging from preterm neonates to adults. Br J Clin Pharmacol. 2014;77(1):149-59.

51. Wang C, Sadhavisvam S, Krekels EH, Dahan A, Tibboel D, Danhof M, et al. Developmental changes in morphine clearance across the entire paediatric age range are best described by a bodyweight-dependent exponent model. Clin Drug Investig. 2013;33(7):523-34.

52. Bjorkman S. Prediction of cytochrome p450-mediated hepatic drug clearance in neonates, infants and children : how accurate are available scaling methods? Clin Pharmacokinet. 2006;45(1):1-11.

53. Strougo A, Yassen A, Monnereau C, Danhof M, Freijer J. Predicting the "first dose in children" of CYP3A-metabolized drugs: evaluation of scaling approaches and insights into the CYP3A7- 
CYP3A4 switch at young ages. J Clin Pharmacol. 2014;54(9):1006-15.

54. Loebstein R, Koren G. Clinical pharmacology and therapeutic drug monitoring in neonates and children. Pediatr Rev. 1998;19(12):423-8.

55. Sethi PK, White CA, Cummings BS, Hines RN, Muralidhara S, Bruckner JV. Ontogeny of plasma proteins, albumin and binding of diazepam, cyclosporine, and deltamethrin. Pediatr Res. 2016;79(3):409-15.

56. Johnson TN, Rostami-Hodjegan A. Resurgence in the use of physiologically based pharmacokinetic models in pediatric clinical pharmacology: parallel shift in incorporating the knowledge of biological elements and increased applicability to drug development and clinical practice. Paediatr Anaesth. 2011;21(3):291-301.
57. Maharaj AR, Barrett JS, Edginton AN. A workflow example of PBPK modeling to support pediatric research and development: case study with lorazepam. AAPS J. 2013;15(2):455-64.

58. Wan H, Bold P, Larsson LO, Ulander J, Peters S, Lofberg B, et al. Impact of input parameters on the prediction of hepatic plasma clearance using the well-stirred model. Curr Drug Metab. 2010;11(7):583-94.

59. Hinderling PH. Red blood cells: a neglected compartment in pharmacokinetics and pharmacodynamics. Pharmacol Rev. 1997;49(3):279-95.

60. Vet NJ, Brussee JM, de Hoog M, Mooij MG, Verlaat CW, Jerchel IS, et al. Inflammation and organ failure severely affect midazolam clearance in critically ill children. Am J Respir Crit Care Med. 2016;194(1):58-66. 